\title{
Infliximab maintains a high degree of clinical response in patients with active psoriatic arthritis through 1 year of treatment: results from the IMPACT 2 trial
}

\author{
A Kavanaugh, G G Krueger, A Beutler, C Guzzo, B Zhou, L T Dooley, P J Mease, D D Gladman, \\ K de Vlam, P P Geusens, C Birbara, D G Halter, C Antoni, for the IMPACT 2 Study Group
}

See end of article for authors' affiliations

Correspondence to: Dr A Kavanaugh, Center for Innovative Therapy, Division of Rheumatology, Allergy and Immunology, University of California at San Diego, 9500 Gilman Drive, La Jolla, CA 92093-0943, USA; akavanaugh@ucsd.edu

Accepted 30 October 2006 Published Online First 17 November 2006

\begin{abstract}
Objective: To evaluate the efficacy and safety of infliximab through 1 year in patients with psoriatic arthritis (PsA) enrolled in the IMPACT 2 trial.

Methods: In this double blind, placebo controlled, phase III study, 200 patients with active PsA were randomised to receive infusions of infliximab $5 \mathrm{mg} / \mathrm{kg}$ or placebo at weeks $0,2,6$, and every 8 weeks thereafter through 1 year. Patients with persistent disease activity could enter early escape at week 16 , and all remaining placebo patients crossed over to infliximab at week 24. Patients randomised to infliximab who had no response or who lost response could escalate their dose to $10 \mathrm{mg} / \mathrm{kg}$ starting at week 38 . Clinical efficacy was assessed based on the proportion of patients achieving ACR 20 and PASI 75 responses. Major clinical response (that is, maintenance of ACR 70 response for 24 continuous weeks) was assessed for the first time in PsA.

Results: Through 1 year of treatment, $58.9 \%$ and $61.4 \%$ of patients in the randomised infliximab and placebo/infliximab groups, respectively, achieved ACR 20; corresponding figures for PASI 75 were $50.0 \%$ and $60.3 \%$. At week 54 , major clinical response was achieved by $12.1 \%$ of patients in the infliximab group. The safety profile of infliximab through week 54 was consistent with that seen through week 24 . Two malignancies occurred: basal cell skin cancer (placebo) and stage I Hodgkin's lymphoma (infliximab).

Conclusion: Infliximab maintains a high degree of clinical efficacy and continues to be well tolerated in patients with PsA through 1 year of treatment.
\end{abstract}

$P$ soriatic arthritis (PsA), an inflammatory arthropathy occurring in $6-39 \%$ of patients with psoriasis, ${ }^{1-3}$ can result in substantial morbidity, ${ }^{45}$ increased mortality, ${ }^{67}$ and impaired physical function and quality of life. ${ }^{8-10}$ The proinflammatory cytokine, tumour necrosis factor $\alpha(\mathrm{TNF} \alpha)$, has a key role in the pathogenesis of this disease, ${ }^{11-18}$ and the efficacy of biological agents that neutralise TNF $\alpha$ has been demonstrated in several studies of patients with PsA. ${ }^{19-24}$

IMPACT 2 was a 54 week, multicentre study of infliximab $5 \mathrm{mg} / \mathrm{kg}$ in patients with active PsA. The 1 year efficacy and safety findings from IMPACT 2 in this report expand the published clinical response data from the initial, 24 week, double blind, placebo controlled period. ${ }^{21}$ The study design allowed for evaluation of changes in skin and joint efficacy measures in patients initially randomised to placebo and then switched to infliximab relative to those receiving 1 year of infliximab treatment. This report evaluates the effect of concomitant methotrexate (MTX) use on the efficacy and safety profile in patients with PsA and, further, it assesses the effect of infliximab dose escalation from 5 to $10 \mathrm{mg} / \mathrm{kg}$ on arthritis and skin response. It also presents the effect of long term infliximab treatment on PsA-specific features of joint disease, such as dactylitis and enthesopathy, and on quality of life and physical function. The first report of major clinical response in PsA based on a definition used to evaluate patients with rheumatoid arthritis-that is, maintenance of the American College of Rheumatology (ACR) 70 response for at least 6 consecutive months-is generated.

\section{PATIENTS AND METHODS}

Patients

Details of patient eligibility criteria for the IMPACT 2 study have been published previously. ${ }^{21}$ Briefly, 200 adult patients with active PsA were enrolled. Active disease was defined as five or more swollen joints and five or more tender joints and either $\mathrm{C}$ reactive protein levels of at least $15 \mathrm{mg} / \mathrm{l}$ or morning stiffness lasting 45 minutes or longer, or both. All patients had active psoriasis, with at least one plaque of $2 \mathrm{~cm}$ or greater in diameter. A negative rheumatoid factor result and an inadequate response to current or previous disease modifying antirheumatic drugs or non-steroidal anti-inflammatory drugs (NSAIDs) were also required. Concomitant MTX treatment (up to $25 \mathrm{mg} / \mathrm{wk}$ ) was allowed but not mandatory.

\section{Study design}

The details of the study design have been reported previously. ${ }^{21}$ Patients in this phase III, multicentre, double blind, placebo controlled study were randomised ( $1: 1)$ to infliximab $5 \mathrm{mg} / \mathrm{kg}$ (Remicade, Centocor, Inc, Malvern, PA, USA) or placebo as induction treatment at weeks 0,2 , and 6 followed by infusions at weeks 14 and 22 through week 24, at which time patients receiving placebo crossed over to active treatment; all patients received infliximab for the remainder of the 54 week study. Based on predefined criteria (that is, $<10 \%$ improvement from baseline in both swollen and tender joint counts), placebo patients could enter early escape to infliximab at week 16. To maintain the blind, patients in the infliximab group meeting the same definition of lack of response also entered early escape

Abbreviations: $A C R$, American College of Rheumatology; $A E$, adverse event; ALT, alanine aminotransferase; anti dsDNA, antibodies to double stranded DNA; AST, aspartate aminotransferase; ANAs, antinuclear antibodies; BSA, body surface area; $\mathrm{HAQ}$, Health Assessment

Questionnaire; MTX, methotrexate; NSAIDs, non-steroidal antiinflammatory drugs; PASI, Psoriasis Area and Severity Index; PsA, psoriatic arthritis; PsARC, Psoriatic Arthritis Response Criteria; SAE, serious adverse effect; SF-36, Short Form-36; TNF $\alpha$, tumour necrosis factor $\alpha$ 


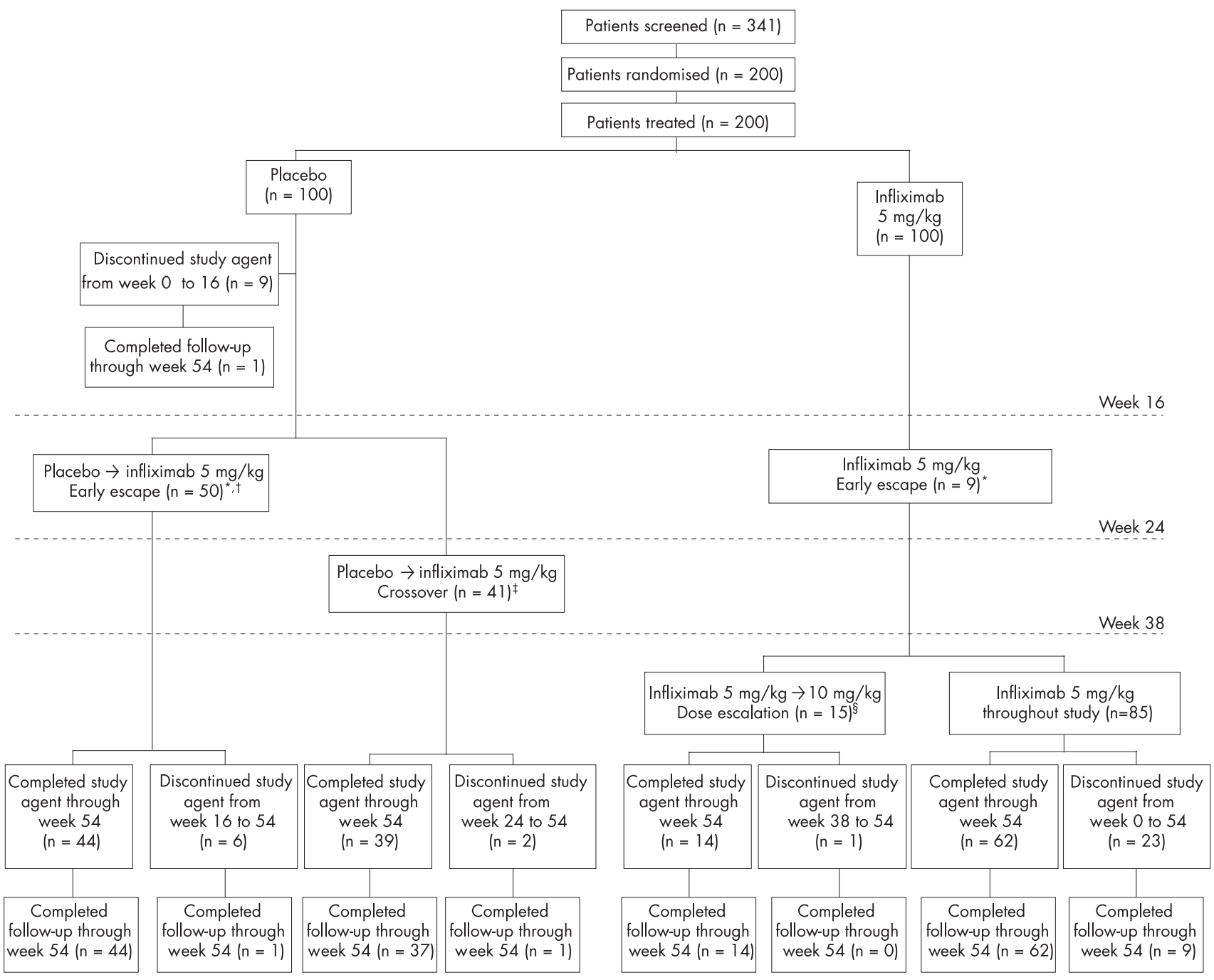

Figure 1 Patient disposition chart, including patients who entered early escape, escalated the infliximab dose, or discontinued the study or study agent. *Any patient in either treatment group with $<10 \%$ improvement from baseline in both tender and swollen joints entered early escape to active treatment at week 16.

tIncludes 3 patients in the placebo group who received infliximab at week 0 in error.

$\ddagger$ All patients in the placebo group crossed over to active treatment at week 24 .

§Any patient in the infliximab group with $<20 \%$ improvement from baseline in combined tender and swollen joints had their infliximab dose increased to $10 \mathrm{mg} / \mathrm{kg}$ at weeks 38 and 46 .

by receiving additional placebo infusions but continued to receive infliximab on the original dosing schedule. Patients randomised to infliximab who had $<20 \%$ improvement from baseline in the combined number of swollen and tender joints at week 38 could also escalate their dose from 5 to $10 \mathrm{mg} / \mathrm{kg}$ at weeks 38 and 46 .

\section{Study procedures and evaluations \\ Clinical efficacy}

Clinical efficacy was assessed by the ACR core set, ${ }^{25}$ the Psoriatic Arthritis Response Criteria (PsARC), ${ }^{26}$ and duration of morning stiffness. Major clinical response was defined as maintenance of ACR 70 response for a 24 week continuous period. ${ }^{27}$ The presence and severity of dactylitis (on a scale of 0 3 ) were assessed in the hands and feet, and the presence of active enthesopathy was evaluated in the feet. ${ }^{21}$ In patients with at least 3\% body surface area (BSA) psoriasis at baseline, psoriasis activity was assessed using the Psoriasis Area and Severity Index (PASI) ${ }^{28}$ Regardless of baseline BSA, the target skin lesion was assessed for scaling, erythema, and plaque induration on a scale of 0 to 4 . Functional status was evaluated using the Disability Index of the Health Assessment Questionnaire (HAQ) $)^{29}$; a decrease of at least 0.3 in HAQ was considered clinically significant. ${ }^{30}$ Health-related quality of life was evaluated using the Short Form-36 (SF-36).31

\section{Safety evaluations}

Adverse events (AEs) and routine haematology and chemistry variables were evaluated at every visit through week 54 . Blood samples were drawn to determine the presence of antibodies to infliximab through week 66 (20 weeks after the last infusion) and antinuclear antibodies (ANAs; antibody titre of $1 / 160$ or more was considered positive) through week 54. Samples positive for ANAs were tested for the presence of antibodies to double stranded DNA (anti-dsDNA).

\section{Statistical methods}

A sample size of 200 patients was chosen to ensure an adequate safety evaluation. With 100 patients in each group, the study 
Table 1 Baseline characteristics of the patients

\begin{tabular}{|c|c|c|}
\hline Characteristics & Placebo & $\begin{array}{l}\text { Infliximab } \\
5 \mathrm{mg} / \mathrm{kg}\end{array}$ \\
\hline Patients randomised ( $\mathrm{n}$ ) & 100 & 100 \\
\hline Female sex $(\%)$ & 49.0 & 29.0 \\
\hline Age (years)* ${ }^{*}$ & $46.5(11.3)$ & $47.1(12.8)$ \\
\hline Weight $(\mathrm{kg})^{*}$ & $84.5(20.3)$ & $87.9(16.5)$ \\
\hline \multicolumn{3}{|l|}{ PsA subtype (\%) } \\
\hline Arthritis involving DIPs & 23.0 & 26.0 \\
\hline Arthritis mutilans & 2.0 & 1.0 \\
\hline Asymmetric peripheral arthritis & 22.0 & 18.0 \\
\hline Polyarticular arthritis & 47.0 & 53.0 \\
\hline Spondylitis with peripheral arthritis & 6.0 & 2.0 \\
\hline PsA duration (years)* & $7.5(7.8)$ & $8.4(7.2)$ \\
\hline \multicolumn{3}{|l|}{ ACR component* } \\
\hline Number of swollen joints (0-66) & $14.4(8.9)$ & $13.9(7.9)$ \\
\hline Number of tender joints $(0-68)$ & $25.1(13.3)$ & $24.6(14.1)$ \\
\hline CRP (mg/l) & $23(34)$ & $19(21)$ \\
\hline Physician's global assessment of disease activity (VAS; $0-10 \mathrm{~cm}$ ) & $5.9(1.7)$ & $5.5(1.8)$ \\
\hline Patient's global assessment of disease activity (VAS; $0-10 \mathrm{~cm}$ ) & $5.9(2.2)$ & $5.4(2.1)$ \\
\hline Patient's assessment of pain (VAS; $0-10 \mathrm{~cm}$ ) & $5.9(2.3)$ & $5.6(2.1)$ \\
\hline $\mathrm{HAQ}$ disability index $(0-3)$ & $1.1(0.6)$ & $1.1(0.6)$ \\
\hline Duration of morning stiffness $(0-1440 \mathrm{~min})^{*}$ & $183.4(308.8)$ & $216.0(376.0)$ \\
\hline Patients with one or more digits with dactylitis (\%) & 41.0 & 40.0 \\
\hline Patients with enthesopathy $(\%)$ & 35.0 & 42.0 \\
\hline Psoriasis duration (years) ${ }^{*}$ & $16.8(12.0)$ & $16.2(11.0)$ \\
\hline \multicolumn{3}{|l|}{ Psoriasis evaluation } \\
\hline Patients with $\geqslant 3 \%$ BSA with psoriasis (\%) & 87.0 & 83.0 \\
\hline PASI score $(0-72)^{*}$ & $10.2(9.0)$ & $11.4(12.7)$ \\
\hline Patients with PASI $\geqslant 10$ & 31.0 & 30.0 \\
\hline Target lesion score $(0-12)^{*}$ & $6.2(1.9)$ & $5.9(2.2)$ \\
\hline \multicolumn{3}{|l|}{ SF-36 score* } \\
\hline Physical component (0-100) & $31.0(9.0)$ & $33.0(9.4)$ \\
\hline Mental component (0-100) & $47.0(11.9)$ & $45.5(11.9)$ \\
\hline \multicolumn{3}{|l|}{ Baseline drug } \\
\hline Patients taking MTX (\%) & 45.0 & 47.0 \\
\hline MTX dose (mg/week)* & $14.8(5.4)$ & $16.2(5.2)$ \\
\hline Patients taking oral corticosteroids (\%) & 10.0 & 15.0 \\
\hline Patients taking NSAIDs (\%) & 73.0 & 71.0 \\
\hline
\end{tabular}

had at least $90 \%$ power to detect a significant treatment difference in the proportion of ACR 20 responders at week 24. At randomisation, patients were stratified by baseline MTX use and investigational site. The primary analysis was based on all randomised patients according to the treatment assigned. Patients with missing ACR data and those who entered early escape at week 16 were considered non-responders at week 24 . For the PASI analyses at week 24, the last observation before week 16 was carried forward. Analyses at week 54 were based on the subset of patients who completed study evaluations and included patients with imputed data based on treatment failure rules. Treatments were considered to have failed if infusions were discontinued for lack of efficacy, if they lost response, if prohibited treatment was started or the concomitant dose of the drug was increased, or if patients underwent more than two surgical joint procedures for PsA. For these patients, the percentage change for ACR response was imputed to 0 . Patients with missing data for other reasons were excluded. All efficacy analyses presented were prespecified, unless otherwise noted.

Data were summarised using descriptive summary statistics for continuous variables, and counts and percentages for discrete variables. The Cochran-Mantel-Haenszel $\chi^{2}$ test stratified by baseline MTX usage was used to analyse the co-primary end point of ACR 20 response at week 14 and other secondary end points with categorical data. A two sided F test using an analysis of variance method with baseline MTX usage as a factor on the van der Waerden normal scores was employed to analyse end points with continuous data.

Safety analyses were performed using data from patients who received at least one infusion of infliximab, regardless of treatment assignment. Safety data through week 54 are presented for the placebo group (that is, only data before the first dose of infliximab reported) and the combined infliximab group (that is, data for patients randomised to infliximab and data from week 16 onward for patients randomised to placebo who entered early escape at week 16, from week 24 onward for those who crossed over to infliximab at week 24 , and from the first dose of infliximab onward for those who received a dose of infliximab in error).

\section{RESULTS}

Baseline characteristics and patient disposition

Figure 1 summarises patient disposition through week 54 . With the exception of the distribution of men and women, 
Table 2 Clinical responses at week 24 and week 54

\begin{tabular}{|c|c|c|c|c|c|}
\hline \multirow[b]{2}{*}{ Responses } & \multicolumn{3}{|l|}{ Week 24} & \multicolumn{2}{|l|}{ Week 54} \\
\hline & Placebo & $\begin{array}{l}\text { Infliximab } \\
5 \mathrm{mg} / \mathrm{kg}\end{array}$ & $\mathrm{p}$ Value & $\begin{array}{l}\text { Placebo/ } \\
\text { infliximab* }\end{array}$ & $\begin{array}{l}\text { Randomised } \\
\text { infliximabt }\end{array}$ \\
\hline Number of patients & 100 & 100 & & 83 & 90 \\
\hline \multicolumn{6}{|l|}{ ACR responseł } \\
\hline $20 \%$ Improvement (\%) & 16.0 & 54.0 & $<0.001$ & 61.4 & 58.9 \\
\hline $50 \%$ Improvement $(\%)$ & 4.0 & 41.0 & $<0.001$ & 43.4 & 36.7 \\
\hline $70 \%$ Improvement (\%) & 2.0 & 27.0 & $<0.001$ & 25.3 & 22.2 \\
\hline Achieving PsARC (\%) & 32.0 & 70.0 & $<0.001$ & 81.9 & 74.4 \\
\hline \multicolumn{6}{|l|}{ Percentage improvement in individual ACR components $\ddagger$, § } \\
\hline Number of swollen joints & $23.5(39.8)$ & $58.0(45.3)$ & $<0.001$ & $57.5(62.5)$ & $59.6(54.9)$ \\
\hline Number of tender joints & $14.9(36.5)$ & $54.1(45.2)$ & $<0.001$ & $54.8(53.0)$ & $52.0(46.8)$ \\
\hline CRP & $-7.0(55.0)$ & $34.7(67.5)$ & $<0.001$ & $16.6(108.2)$ & $8.3(136.4)$ \\
\hline Physician's global assessment of disease activity (VAS) & $18.0(55.9)$ & $57.3(46.8)$ & $<0.001$ & $66.5(46.1)$ & $62.6(39.7)$ \\
\hline Patient's global assessment of disease activity (VAS) & $7.2(45.4)$ & $35.1(74.4)$ & $<0.001$ & $45.9(56.8)$ & $31.3(78.6)$ \\
\hline Patient's assessment of pain (VAS) & $-10.0(114.2)$ & $37.4(54.2)$ & $<0.001$ & $48.9(53.3)$ & $38.9(63.6)$ \\
\hline $\mathrm{HAQ}$ disability index & $-19.4(102.8)$ & $46.0(42.5)$ & $<0.001$ & $35.5(103.7)$ & $41.2(89.4)$ \\
\hline \multicolumn{6}{|l|}{ Absolute values for individual ACR components $\$$} \\
\hline Number of swollen joints $(0-66)$ & $11.7(9.7)$ & $5.6(6.9)$ & $<0.001$ & $6.7(9.5)$ & $5.1(7.3$ \\
\hline Number of tender joints $(0-68)$ & $21.1(13.4)$ & $12.5(15.1)$ & $<0.001$ & $11.9(15.0)$ & $13.0(15.7)$ \\
\hline CRP (mg/l) & $22(32))$ & $7(8)$ & $<0.001$ & $10(16)$ & $10(15)$ \\
\hline Physician's global assessment of disease activity (VAS; $0-10 \mathrm{~cm}$ ) & $4.5(2.4)$ & $2.2(2.2)$ & $<0.001$ & $1.9(2.2)$ & $2.0(2.3)$ \\
\hline Patient's global assessment of disease activity (VAS; $0-10 \mathrm{~cm}$ ) & $5.0(2.5)$ & $3.0(2.5)$ & $<0.001$ & $2.8(2.7)$ & $3.0(2.6)$ \\
\hline Patient's assessment of pain (VAS; $0-10 \mathrm{~cm}$ ) & $5.2(2.6)$ & $3.1(2.6)$ & $<0.001$ & $2.7(2.7)$ & $3.1(2.7)$ \\
\hline HAQ Disability Index (0-3) & $1.1(0.7)$ & $0.7(0.7)$ & $<0.001$ & $0.7(0.8)$ & $0.6(0.7)$ \\
\hline Percentage improvement in duration of morning stiffness§ & $-152.0(882.6)$ & $43.1(103.9)$ & $<0.001$ & $29.0(330.7)$ & $12.4(281.5)$ \\
\hline Patients with at least one digit with dactylitis (\%) & 34.0 & 11.8 & $<0.001$ & 14.8 & 12.2 \\
\hline Patients with enthesopathy $(\%)$ & 37.2 & 20.4 & 0.002 & 19.8 & 18.9 \\
\hline \multicolumn{6}{|l|}{ PASI responseł } \\
\hline Patients with $\geqslant 3 \%$ BSA affected with psoriasis (baseline), $n$ & 87 & 83 & & 73 & 72 \\
\hline$\geqslant 50 \%$ Improvement $(\%)$ & 8.0 & 74.7 & $<0.001$ & 79.5 & 69.4 \\
\hline$\geqslant 75 \%$ Improvement (\%) & 1.1 & 60.2 & $<0.001$ & 60.3 & 50.0 \\
\hline$\geqslant 90 \%$ Improvement (\%) & 0.0 & 38.6 & $<0.001$ & 42.5 & 41.7 \\
\hline Percentage improvement in target lesion score $\ddagger$, § & $-1.0(40.1)$ & $64.2(43.9)$ & $<0.001$ & $70.3(38.1)$ & $53.6(50.4)$ \\
\hline Change in SF-36, n‡, § & 92 & 93 & & & \\
\hline Physical component & $1.3(8.2)$ & $7.7(9.8)$ & 0.001 & $10.7(10.4)$ & $8.8(10.6)$ \\
\hline Mental component & $0.4(11.6)$ & $3.9(11.9)$ & 0.047 & $2.8(10.3)$ & $3.7(9.5)$ \\
\hline \multicolumn{6}{|c|}{$\begin{array}{l}\text { *This group includes patients who were randomised to placebo and received infliximab, starting at either week } 16 \text { or } 24 \text {; } \text { this group includes patients who were } \\
\text { randomised to infliximab } 5 \mathrm{mg} / \mathrm{kg} \text { and either received infliximab } 5 \mathrm{mg} / \mathrm{kg} \text { throughout the study or escalated the dose to } 10 \mathrm{mg} / \mathrm{kg} \text { at week } 38 \text { and } 46 \text {; } \neq \text { values are } \\
\text { change or improvement from baseline; } \text { Svalues are means (standard deviation). } \\
\text { ACR, American College of Rheumatology; BSA, body surface area; CRP, C reactive protein; HAQ, Health Assessment Questionnaire; PASI, Psoriasis Area and Severity } \\
\text { Index; PsARC, Psoriatic Arthritis Response Criteria; SF-36, Short Form-36; VAS, visual analogue scale. }\end{array}$} \\
\hline
\end{tabular}

demographics and baseline disease characteristics were similar between treatment groups (table 1).

Post hoc analyses suggested that the demographic characteristics of patients randomised to placebo who entered early escape at week 16 did not differ from those of patients who crossed over to infliximab at week 24 (data not shown). However, the demographics of the small number of infliximab randomised patients who required dose escalation from 5 to $10 \mathrm{mg} / \mathrm{kg}$ at week 38 were different from those in patients who did not increase their dose. Patients who escalated their infliximab dose were older (mean age $55.0 \vee 45.9$ years) and higher proportions were taking MTX $(66.7 \% \quad v \quad 44.1 \%)$ or NSAIDs $(86.7 \% \quad v 67.7 \%)$ or had arthritis affecting distal interphalangeal joints (46.7\% $v 23.5 \%)$.

\section{Efficacy}

As previously reported, patients receiving infliximab $5 \mathrm{mg} / \mathrm{kg}$ had significantly better outcomes than those receiving placebo for joint response (ACR criteria, enthesopathy, and dactylitis), skin response (PASI), physical function (HAQ), and quality of life (SF-36) at week 24 (table 2). ${ }^{21}$

\section{Joint response}

Through week 54, ACR 20, ACR 50, and ACR 70 responses were maintained with continued infliximab treatment in the randomised infliximab group and were substantial after crossover to infliximab in the placebo/infliximab group (table 2; fig 2). The ACR response at week 54 was consistent, regardless of baseline MTX use (for example, 56.8\% of patients receiving infliximab plus MTX and $60.9 \%$ of patients receiving infliximab only achieved ACR 20 response). A major clinical response was achieved by $12.1 \%$ of patients in the infliximab group at week 54.

By week 54, there was a marked decrease from baseline in the numbers of patients with active enthesopathy and with at least one dactylitis digit in both treatment groups (table 2). Other efficacy results, including the proportion of patients achieving PsARC, percentage improvement in individual ACR components, and duration of morning stiffness, confirmed the maintenance of efficacy of infliximab through week 54. Furthermore, by week 54, all efficacy measures improved in the placebo/infliximab group to an extent similar to that in the randomised infliximab group. 

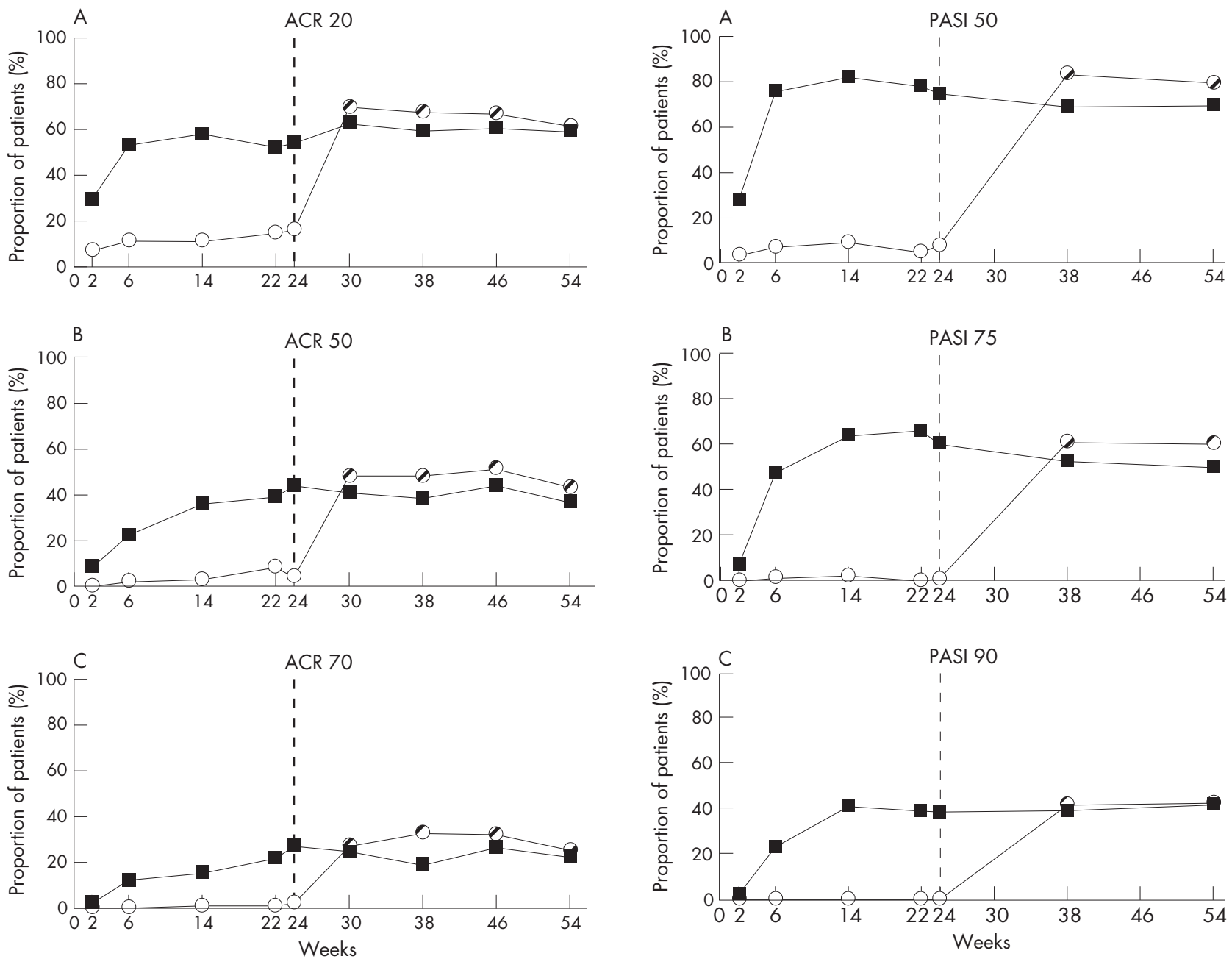

$$
\begin{aligned}
& \text { - Placebo Infliximab } 5 \mathrm{mg} / \mathrm{kg} \\
& - \text { - Placebo crossover to infliximab } 5 \mathrm{mg} / \mathrm{kg} \text { (week 24) }
\end{aligned}
$$

Figure 2 Joint response over time through week 54, as measured by various degrees of ACR response in patients treated with infliximab and/or placebo. Data are reported for 100 patients and 90 patients in the infliximab groups and 100 and 83 patients in the placebo groups at weeks 24 and 54, respectively. ACR = American College of Rheumatology.

\section{Skin response}

Through week 54, the PASI 75 and PASI 90 responses seen at week 24 were generally maintained in the randomised infliximab group (table 2; fig 3). By week 54, similar proportions of patients achieved both PASI 75 and PASI 90 across treatment groups (table 2; fig 3). Compared with patients not receiving MTX at baseline, those receiving MTX in combination with infliximab had similar PASI 75 responses at week 54 (that is, $47.5 \%$ and $53.1 \%$, respectively).

\section{Effect of dose escalation}

Among the 15 patients who were randomised to infliximab $5 \mathrm{mg} / \mathrm{kg}$ but whose dose was escalated to $10 \mathrm{mg} / \mathrm{kg}$ at week 38 (that is, by definition did not achieve an ACR 20 response), nine had previously achieved an ACR 20 response and six had not. Among these nine patients, five also achieved an ACR 20 response at week 54 . None of the six patients who failed to respond through week 38 achieved an ACR 20 response after was escalated had baseline BSA of at least 3\% and were included in the PASI analyses. Of these 12 patients, five achieved PASI 75 at week 38, and all five maintained PASI 75 response at week 54 . Conversely, the seven patients who did not achieve PASI at week 38 were unable to achieve the response after dose escalation. Post hoc analyses showed that body mass index did not affect PASI response to dose escalation (data not shown).

Physical function and quality of life

By week 54, the percentage improvement in HAQ was markedly better than at baseline in both treatment groups (table 2). At week 54,58.9\% in the randomised infliximab group and 53.0\% in the placebo/infliximab group had achieved a clinically significant change ( $\geqslant 0.3$ units decrease) in HAQ. Through week 54, the mean improvement in SF-36 achieved at week 24 was maintained in the randomised infliximab group and was 
similar between treatment groups for both the Physical Component Summary score and the Mental Component Summary score (table 2).

\section{Safety}

The safety profile of infliximab through week 54 was consistent with that observed through week 24 . About $85 \%$ of patients experienced an $\mathrm{AE}$ in the combined infliximab group at week 54 and $67 \%$ at week 24 . The incidence of AEs in the combined infliximab group was generally similar between patients receiving MTX (87.5\%) and those not receiving MTX (82.5\%) at baseline. Twenty two patients (11.5\%) in the combined infliximab group experienced a serious adverse event (SAE) through week 54; one patient whose dose was escalated experienced worsening of pre-existing carotid arterial stenosis that required surgery about 4 months after the last infusion.

Sixteen patients $(8.4 \%)$ in the combined infliximab group had infusions stopped owing to an AE; seven of these patients had raised liver function tests. Two patients in the placebo group (cellulitis, bronchitis) and three in the infliximab group (infectious hepatitis, cellulitis, and pneumonia) experienced serious infections. Two patients had malignancies: one placebo patient had basal cell carcinoma and one infliximab patient, who had been treated with MTX and alefacept before the study, had stage I Hodgkin's lymphoma. No reports of tuberculosis or opportunistic infection, autoimmune disorders, central demyelinating events, or congestive heart failure were received.

Infusion reactions were reported with $2.1 \%$ of infusions in the combined infliximab group and $1.6 \%$ of infusions in patients receiving placebo only. In the combined infliximab group, the infusion reaction rate was lower in patients receiving MTX at baseline $(0.9 \% \vee 3.2 \%$ without MTX). Most infusion reactions were mild to moderate, and none were considered serious. No anaphylactic reactions or delayed hypersensitivity reactions occurred.

Of the 15 patients in whom the dose of infliximab was escalated to $10 \mathrm{mg} / \mathrm{kg}$, four (27\%) experienced at least one SAE from baseline through week 54. These SAEs included arthralgia, bone fracture, extracardiac aneurysm, abdominal hernia, and carotid arterial stenosis, the last of which was the only SAE that occurred after dose escalation. Twelve of these 15 patients experienced an $\mathrm{AE}$ of infection from baseline through week 54, although none were considered SAEs, and only three patients had an infection (including one case of pneumonia) after dose escalation. Through week 54, one patient receiving an escalated dose experienced an infusion reaction and another had a markedly abnormal alanine aminotransferase (ALT) level. One patient discontinued infliximab after dose escalation at week 38 owing to hives, which had also been experienced during previous treatment with the $5 \mathrm{mg} / \mathrm{kg}$ dose.

As reported previously, markedly abnormal ALT and aspartate aminotransferase (AST) values (that is, predefined as $>150$ IU/l and $\geqslant 100 \%$ increase from baseline for ALT and AST) occurred in five patients in the infliximab group through week $24 .{ }^{21}$ Through week 54, markedly abnormal ALT and AST values were reported in 8/191 (4.2\%) and 4/191 (2.1\%) patients, respectively, in the combined infliximab group. These rises occurred in the same patients in whom increases were reported at week 24 and in three additional patients; they resolved in all but one patient who was lost to follow-up. Of the 191 patients in the combined infliximab group, ALT and AST values increased from normal at baseline to high (that is, any value above normal) through week 54 in 81 patients $(42.4 \%)$ and 51 patients $(26.7 \%)$, respectively. Slightly more infliximab treated patients not receiving MTX had an ALT value that rose from normal to high compared with those receiving MTX $(46.6 \% v$ 39.5\%); similar findings were observed for AST (31.1\% v
$21.6 \%)$. Post hoc analyses showed that slightly more male patients had levels changing from normal to high, especially for ALT values (data not shown). Other baseline factors, including body mass index, prior drug treatment for PsA or psoriasis, and drugs for pain, did not affect the proportion of patients with a shift in ALT/AST values from normal to high (data not shown). No cases of liver failure or clinically significant liver dysfunction occurred through week 54.

Through week $66,15.4 \%$ of patients in the combined infliximab group were positive for antibodies to infliximab; most had low antibody titres. As only five patients had a titre above $1 / 80$, the correlation between antibody status and patient outcome could not be evaluated. While only $3.6 \%$ of patients receiving MTX at baseline were positive for antibodies to infliximab, $26.1 \%$ of those not receiving MTX at baseline tested positive. Among the 14 patients receiving an escalated dose with available samples, 2 (14.3\%) were positive for antibodies. Through week $66,41.3 \%$ of the patients in the combined infliximab group were newly positive for ANA, and 8.6\% were newly positive for anti-dsDNA antibodies; however, no patient developed drug-induced lupus. No patients in the placebo-only group were newly positive for anti-dsDNA antibodies. In the combined infliximab group, the median percentage ACR improvement at week 54 for patients who were positive for antibodies to infliximab $(21.7 \%)$ was lower than that for the antibody negative patients $(33.3 \%)$ and for the patients whose test results were inconclusive $(44.8 \%)$. Among antibody positive patients, an approximately 3.5 -fold increase in the incidence of mild to moderate infusion reactions occurred compared with antibody negative subjects; however, no severe or serious infusion reactions or possible delayed-type hypersensitivity or possible anaphylactic reactions were experienced by antibody positive patients.

\section{DISCUSSION}

Several studies have demonstrated the safety and efficacy of anti-TNF $\alpha$ agents in the treatment of PsA. ${ }^{19-24}$ This report demonstrates improvement in the signs and symptoms of arthritis and associated psoriasis, quality of life, and physical function in patients with PsA through 1 year of infliximab treatment, thereby broadening the knowledge of the benefits and risks of long term infliximab treatment, both with and without MTX. One year of treatment with infliximab resulted in a high degree of sustained ACR and PASI response, regardless of concomitant MTX use, in addition to continued benefit with regard to dactylitis and enthesopathy.

Although it was our intention to evaluate infliximab dose escalation in this study, only 15 patients met the predefined criteria for escalation. This suggests that $5 \mathrm{mg} / \mathrm{kg}$ is the appropriate dose for most patients. Interestingly, in the subgroup requiring dose escalation, patients who had not achieved ACR 20 before dose escalation were unable to achieve this response despite doubling the dose of infliximab from 5 to $10 \mathrm{mg} / \mathrm{kg}$. In contrast, patients who demonstrated ACR 20 improvement at some point before dose escalation were able to regain ACR 20 responses by doubling the dose. Dose escalation did not appear to improve PASI responses; however, the protocol requirement for increasing the dose was not contingent upon PASI response. The fact that the percentage of antibody positive patients was similar between patients receiving an escalated dose (14.3\%) and the combined infliximab group (15.4\%) suggests that a positive antibody to infliximab status was not necessarily a factor leading to dose escalation. However, the small number of patients whose dose was increased from 5 to $10 \mathrm{mg} / \mathrm{kg}$ precludes the drawing of definitive inferences about the efficacy and safety of higher doses in patients with PsA. 
Attainment of "major clinical response" (that is, ACR 70 improvement for 24 consecutive weeks) was also evaluated. Designed originally to measure response in patients with rheumatoid arthritis, major clinical response is evaluated here for the first time in a group of patients with PsA. Although this definition confirms a high degree of sustained improvement in arthritis, it does not make provisions for improvement in the dermatological component of the disease. Further research is needed to better identify a definition that is specific for major response in both skin and joint components of PsA and to evaluate the effect of infliximab on major clinical response over time.

Skin response, as measured by PASI, was impressive for both patients treated with infliximab from baseline and those who crossed over to active treatment at week 16 or week 24 . At week 54, more than half of all patients achieved a PASI 75 response and $42 \%$ achieved a PASI 90 response, which is consistent with a clear or almost clear status. Although patients were not randomised to receive MTX, randomisation was stratified by baseline MTX use, and it is especially notable that skin response did not appear to be affected by concomitant MTX use. These results are particularly relevant because, as a dermatological manifestation, psoriasis is a critical factor in decreased quality of life and physical function in patients with PsA. ${ }^{8-10}$ Accordingly, notable improvement was seen with infliximab in the physical and mental aspects of quality of life as well as the ability to function in daily life, indicating that the substantial effects observed at 6 months ${ }^{21}$ continued through 1 year.

Infliximab was generally well tolerated over the 1 year treatment period. The incidence of predefined markedly abnormal transaminase levels, which were higher in the infliximab group than in the placebo group at week 24, did not increase disproportionately with an additional 30 weeks of treatment. Methotrexate use at baseline appeared to result in fewer patients with increases in transaminase levels compared with patients not using MTX. However, the effect of MTX on transaminase levels must be interpreted with caution, as patients receiving MTX before enrolment were required to have tolerated MTX for at least 3 months without significant toxicity, suggesting that these patients may have been less prone to abnormal liver enzymes than the other patients. No cases of opportunistic infections, congestive heart failure, demyelination, or liver failure were reported. One patient treated with infliximab, who had received MTX and alefacept before study entry, was diagnosed with stage I Hodgkin's lymphoma; one placebo patient developed basal skin carcinoma. Fewer infusion reactions occurred among patients receiving MTX at baseline than among those not receiving MTX. However, most infusion reactions were mild to moderate, and no patients developed a serious infusion reaction or anaphylaxis. Similarly, at the end of the study, the proportion of patients positive for antibodies to infliximab was lower among patients receiving MTX at baseline than among those not receiving MTX; however, ACR and PASI responses were consistent irrespective of MTX use.

Through 1 year of infliximab treatment, a high degree of clinical response, as measured by both ACR and PASI responses, was sustained, with corresponding improvements in physical function and quality of life, as measured by the HAQ and SF-36. Infliximab was generally well tolerated. These results indicate that the positive benefit/risk ratio of infliximab seen at 6 months remains favourable after 1 year of treatment in patients with PsA.

\section{ACKNOWLEDGEMENTS}

We acknowledge $C$ Arnold of Centocor, Inc for her editorial assistance and writing support in the preparation of this manuscript.

\section{Authors' affiliations}

A Kavanaugh, Center for Innovative Therapy, Division of Rheumatology, Allergy, and Immunology, University of California at San Diego, La Jolla, CA, USA

G G Krueger, University of Utah Health Sciences Center, Salt Lake City, UT, USA

A Beutler, C Guzzo, B Zhou, L T Dooley, Centocor, Inc, Malvern, PA, USA

P J Mease, Seattle Rheumatology Associates, Swedish Medical Center, Seattle, WA, USA

D D Gladman, University of Toronto, Toronto, ON, Canada

$K$ de Vlam, University Hospital Leuven, Leuven, Belgium

P P Geusens, University Hasselt, Diepenbeek, Belgium, and University Hospital, Maastricht, The Netherlands

C Birbara, University of Massachusetts School of Medicine, Worcester, MA, USA

D G Halter, Houston Institute for Clinical Research, Houston, TX, USA

C Antoni, Schering Plough Corp., Kenilworth, NJ, USA

Funding: The IMPACT 2 study was sponsored by Centocor, Inc in Malvern, Pennsylvania, and Schering-Plough Corp in Kenilworth, New Jersey.

Competing interests: A Kavanaugh and DG Halter have received funds for research from Centocor, Inc and its competitors. GG Krueger and C Birbara have received speaking and consulting fees from Centocor, Inc and its competitors. PJ Mease has received research grants and consulting and speaking fees from Centocor, Inc and its competitors. DD Gladman has received consulting fees and research support from Centocor, Inc and Schering Canada. K de Vlam has received consulting fees and reimbursement for attending symposia from Schering-Plough Corp PP Geusens has no competing interests to declare. C Antoni, who was affiliated with the Friedrich Alexander University of Erlangen-Nurnberg, Erlangen, Germany, at the time the study was conducted, is now a full time employee of Schering-Plough Corp, Kenilworth, New Jersey; he has received reimbursement for symposia and funds for research, consulting, speaking, and organising education from Centocor, Inc and its competitors. A Beutler, $C$ Guzzo, B Zhou, and LT Dooley are employees of, and hold stock in, Centocor, Inc, Malvern, Pennsylvania, USA.

\section{REFERENCES}

1 Shbeeb M, Uramoto KM, Gibson LE, O'Fallon WM, Gabriel SE. The epidemiology of psoriatic arthritis in Olmsted County, Minnesota, USA, 19821991. J Rheumatol 2000;27:1247-50.

2 Leonard DG, O'Duffy JD, Rogers RS III. Prospective analysis of psoriatic arthritis in patients hospitalized for psoriasis. Mayo Clin Proc 1978;53:511-18.

3 Gelfand JM, Gladman DD, Mease PJ, Smith N, Margolis DJ, Nijsten T, et al. Epidemiology of psoriatic arthritis in the population of the United States. J Am Acad Dermatol 2005;53:573-7.

4 Gladman DD, Antoni C, Mease P, Clegg DO, Nash P. Psoriatic arthritis: epidemiology, clinical features, course, and outcome. Ann Rheum Dis 2005;64(suppl II):ii14-17.

5 Gladman DD, Shuckett R, Russell ML, Thorne JC, Schachter RK. Psoriatic arthritis (PSA) - an analysis of 220 patients. QJM 1987;62:127-41

6 Wong K, Gladman DD, Husted J, Long JA, Farewell VT. Mortality studies in psoriatic arthritis: results from a single outpatient clinic. I. Causes and risk of death. Arthritis Rheum 1997:40:1868-72.

7 Gladman DD, Farewell VT, Wong K, Husted J. Mortality studies in psoriatic arthritis: results from a single outpatient center. II. Prognostic indicators for death Arthritis Rheum 1998:41:1103-10.

8 Sokoll KB, Helliwell PS. Comparison of disability and quality of life in rheumatoid and psoriatic arthritis. J Rheumatol 2001;28:1842-6.

9 Husted JA, Gladman DD, Farewell VT, Cook RJ. Health-related quality of life of patients with psoriatic arthritis: a comparison with patients with rheumatoid arthritis. Arthritis Rheum 2001;45:151-8.

10 Kavanaugh A, Antoni C, Krueger GG, Yan S, Bala M, Dooley LT, et al. Infliximab improves health-related quality of life and physical function in patients with psoriatic arthritis. Ann Rheum Dis 2006:65:471-7.

11 Mease P. TNF $\alpha$ therapy in psoriatic arthritis and psoriasis. Ann Rheum Dis 2004;63:755-8

12 Mastroianni A, Minutilli E, Mussi A, Bordignon V, Trento E, D'Agosto G, et al. Cytokine profiles during infliximab monotherapy in psoriatic arthritis. Br J Dermatol 2005; 153:531-6.

13 Austin LM, Ozawa M, Kikuchi T, Walters IB, Krueger JG. The majority of epidermal $T$ cells in psoriasis vulgaris lesions can produce type 1 cytokines, interferon-gamma, interleukin-2, and tumor necrosis factor-alpha, defining TC1 (cytotoxic T lymphocyte) and TH1 effector populations: a type 1 differentiation bias is also measured in circulating blood T cells in psoriatic patients. J Invest Dermatol 1999;113:752-9.

14 Partsch G, Steiner G, Leeb BF, Dunky A, Broll H, Smolen JS. Highly increased levels of tumour necrosis factor- $\alpha$ and other proinflammatory cytokines in psoriatic arthritis synovial fluid. J Rheumatol 1997;24:518-23. 
15 Ritchlin C, Haas-Smith SA, Hicks D, Cappuccio J, Osterland CK, Looney RJ. Patterns of cytokine production in psoriatic synovium. J Rheumatol 1998;25:1544-52.

16 Gottlieb AB, Chamian F, Masud S, Cardinale I, Abello MV, Lowes MA, et al. TNF inhibition rapidly down-regulates multiple proinflammatory pathways in psoriasis plaques. J Immunol 2005; 175:2721-9.

17 Hohler T, Kruger A, Schneider PM, Schopf RE, Knop J, Rittner C, et al. A TNFalpha promoter polymorphism is associated with juvenile onset psoriasis and psoriatic arthritis. J Invest Dermatol 1997:109:562-5.

18 Ettehadi P, Greaves MW, Wallach D, Aderka D, Camp RD. Elevated tumour necrosis factor-alpha (TNF- $\alpha$ ) biological activity in psoriatic skin lesions. Clin Exp Immunol 1994;96:146-51.

19 Antoni C, Dechant C, Hanns-Martin Lorenz PD, Wendler J, Ogilvie A, Lueftl M, et al. Open-label study of infliximab treatment for psoriatic arthritis: clinical and magnetic resonance imaging measurements of reduction of inflammation. Arthritis Rheum 2002;47:506-12.

20 Antoni C, Kavanaugh A, Kirkham B, Tutuncu Z, Burmester GR, Schneider U, et al. Sustained benefits of infliximab therapy for dermatologic and articular manifestations of psoriatic arthritis: results from the Infliximab Multinational Psoriatic Arthritis Controlled Trial (IMPACT). Arthritis Rheum 2005;52:1227-36.

21 Antoni C, Krueger GG, de Vlam K, Birbara C, Beutler A, Guzzo C, et al. Infliximab improves signs and symptoms of psoriatic arthritis: results of the IMPACT 2 trial. Ann Rheum Dis 2005:64:1150-7.

22 Mease PJ, Goffe BS, Metz J, VanderStoep A, Finck B, Burge DJ. Etanercept in the treatment of psoriatic arthritis and psoriasis: a randomized trial. Lancet 2000;356:385-90.

23 Mease PJ, Kivitz AJ, Burch FX, Siegel EL, Cohen SB, Ory P, et al. Etanercept treatment of psoriatic arthritis: safety, efficacy, and effect on disease progression. Arthritis Rheum 2004;50:2264-72.

24 Mease PJ, Gladman DD, Ritchlin CT, Ruderman EM, Steinfeld SD, Choy EH, et al. Adalimumab for the treatment of patients with moderately to severely active psoriatic arthritis: results of a double-blind, randomized, placebo-controlled trial. Arthritis Rheum 2005:52:3279-89.

25 Felson DT, Anderson JJ, Boers M, Bombardier C, Furst D, Goldsmith C, et al. American College of Rheumatology preliminary definition of improvement in rheumatoid arthritis. Arthritis Rheum 1995;38:727-35.

26 Clegg DO, Reda DJ, Mejias E, Cannon GW, Weisman MH, Taylor T, et al Comparison of sulfasalazine and placebo in the treatment of psoriatic arthritis: a Department of Veterans Affairs Cooperative study. Arthritis Rheum 1996;39:2013-20.

27 Rheumatology Working Group of the Medical Policy Coordinating Committee (MPCC) of the Center for Drug Evaluation and Research (CDER), the Center for Biologics Evaluation and Research (CBER), the Center for Devices Radiological Health (CDRH). Guidance for the industry: clinical development programs for drugs, devices, and biological products for the treatment of rheumatoid arthritis (RA), 1999. Available at http://www.fda.gov/cber/gdlns/rheumcln.pdf (accessed 13 December 2006).

28 Fredriksson T, Pettersson U. Severe psoriasis: oral therapy with a new retinoid. Dermatologica 1978;157:238-44.

29 Fries JF, Spitz PW, Young DY. The dimensions of health outcomes: the health assessment questionnaire, disability and pain scales. J Rheumatol 1982:9:789-93.
30 Mease PJ, Ganguly R, Wanke L, Yu E, Singh A. How much improvement in functional status is considered important by patients with active psoriatic arthritis: applying the outcome measures in rheumatoid arthritis clinical trials (OMERACT) group guidelines [abstract] Ann Rheum Dis 2004;63(suppl I):391.

31 Ware JE, Sherbourne CD. The MOS 36-item short-form health survey (SF-36). Conceptual framework and item selection. Med Care 1992;30:473-83.

\section{APPENDIX}

We acknowledge the IMPACT 2 investigators:

\section{UNITED STATES}

Dr C Birbara, Worcester, Massachusetts; Dr EP Boling, Upland, California; Dr C Codding, Oklahoma City, Oklahoma; Dr JJ Fiechtner, Lansing, Michigan; Dr RM Fleischmann, Dallas, Texas; Dr SI Goodman, Delray Beach, Florida; Dr AB Gottlieb, New Brunswick, New Jersey; Dr DG Halter, Houston, Texas; Dr JL Harshbarger, Wilmington, North Carolina; Dr K Hobbs, Denver, Colorado; Dr A Kavanaugh, La Jolla, California; Dr SM Lourie, Greenbelt, Maryland; Dr P Mease, Seattle, Washington; Dr A Menter, Dallas, Texas; Dr DM Pariser, Norfolk, Virginia; Dr WJ Shergy, Huntsville, Alabama; Dr EL Siegel, Wheaton, Maryland; Dr DJ Wallace, Los Angeles, California; Dr ME Wenger, Lancaster, Pennsylvania.

\section{CANADA}

Dr R Bissonnette, Montreal, Quebec; Dr J Carter Thorne, New Market, Ontario; Dr DD Gladman, Toronto, Ontario; Dr W Gulliver, St John's, New Foundland; Dr E Keystone, Toronto, Ontario; Dr K Papp, Waterloo, Ontario; Dr Y Poulin, Quebec, Quebec; Dr L Rosoph, North Bay, Ontario.

\section{GERMANY}

Dr C Antoni, Erlangen; Dr G R Burmester, Berlin; Dr C Fiehn, Heidelberg; Dr J Sieper, Berlin; Dr J Wollenhaupt, Hamburg.

\section{BELGIUM}

Dr P Geusens, Diepenbeek; Dr R Westhovens, Leuven.

\section{UNITED KINGDOM}

Dr P Emery, Leeds; Dr B Kirkham, London. 